\title{
Absence of Helicobacter pylori is not protective against peptic ulcer bleeding in elderly on offending agents: lessons from an exceptionally low prevalence population
}

Aim Helicobacter pylori (H. pylori) infection is exceptionally rare in population from the northeastern region of Peninsular Malaysia. This provides us an opportunity to contemplate the future without $H$. pylori in acute non-variceal upper gastrointestinal (GI) bleeding.Methods All cases in the Gl registry with GI bleeding between 2003 and 2006 were reviewed. Cases with confirmed non-variceal aetiology were analysed. Rockall score $>5$ was considered high risk for bleeding and primary outcomes studied were in-hospital mortality, recurrent bleeding and need for surgery. Results The incidence of non-variceal upper GI bleeding was 2.2/100,000 person-years. Peptic ulcer bleeding was the most common aetiology $(1.8 / 100,000$ personyears). In-hospital mortality (3.6\%), recurrent bleeding (9.6\%) and need for surgery $(4.0 \%)$ were uncommon in this population with a largely low risk score $(85.2 \%$ with score $\leq 5)$. Elderly were at greater risk for bleeding (mean 68.5 years, $P=0.01$ ) especially in the presence of duodenal ulcers $(P=0.04)$ despite gastric ulcers being more common. NSAIDs, aspirin and co-morbidities were the main risk factors. Conclusions The absence of $H$. pylori infection may not reduce the risk of peptic ulcer bleeding in the presence of risk factors especially offending drugs in the elderly. 


\section{ORIGINAL ARTICLE}

2 Absence of Helicobacter pylori is not protective against peptic ulcer

3 bleeding in elderly on offending agents: lessons from an 4 exceptionally low prevalence population

5 Yeong Yeh LEE ${ }^{1,2}$, Nordin NORIDAH ${ }^{1}$, Syed Abdul Aziz SYED HASSAN ${ }^{1}$, Jayaram MENON ${ }^{3}$

$6{ }^{1}$ School of Medical Sciences, Universiti Sains Malaysia, Kubang Kerian, Kelantan, Malaysia

$7{ }^{2}$ Section of Gastroenterology \& Hepatology, Department of Medicine, Medical College of

8 Georgia, Georgia Regents University, Augusta, Georgia

$9{ }^{3}$ Department of Medicine, Queen Elizabeth Hospital, Kota Kinabalu, Sabah, Malaysia

10 Corresponding author:

11 Yeong Yeh Lee, MD PhD FACP FRCP

12 School of Medical Sciences

13 Universiti Sains Malaysia

1416150 Kubang Kerian, Kelantan, Malaysia

15 Phone: +6097663000 , Fax: +6097648277

16 E-mail: justnleeyy@gmail.com

17 Running title: non- $H$. pylori ulcer bleeding in elderly

\section{ABSTRACT}

19 Aim Helicobacter pylori (H. pylori) infection is exceptionally rare in population from the north-

20 eastern region of Peninsular Malaysia. This provides us an opportunity to contemplate the future

21 without $H$. pylori in acute non-variceal upper gastrointestinal (GI) bleeding.

22 Methods All cases in the GI registry with GI bleeding between 2003 and 2006 were reviewed.

23 Cases with confirmed non-variceal aetiology were analysed. Rockall score $>5$ was considered

24 high risk for bleeding and primary outcomes studied were in-hospital mortality, recurrent

25 bleeding and need for surgery. 
Results The incidence of non-variceal upper GI bleeding was 2.2/100,000 person-years. Peptic ulcer bleeding was the most common aetiology (1.8/100,000 person-years). In-hospital mortality (3.6\%), recurrent bleeding $(9.6 \%)$ and need for surgery $(4.0 \%)$ were uncommon in this population with a largely low risk score $(85.2 \%$ with score $\leq 5)$. Elderly were at greater risk for bleeding (mean 68.5 years, $P=0.01)$ especially in the presence of duodenal ulcers $(P=0.04)$ despite gastric ulcers being more common. NSAIDs, aspirin and co-morbidities were the main risk factors.

Conclusions The absence of $\mathrm{H}$. pylori infection may not reduce the risk of peptic ulcer bleeding in the presence of risk factors especially offending drugs in the elderly.

Keywords: elderly, Helicobacter pylori, Malays, peptic ulcer, upper gastrointestinal bleeding

\section{INTRODUCTION}

Non-variceal upper gastrointestinal (GI) bleeding remains a prevalent condition and its mortality hardly change despite a declining trend of peptic ulcer disease and improvement in therapeutic approaches. The reported incidence from North America and Europe was 20 60/100,000 populations but data from Asia were unfortunately scarce and variable. ${ }^{1}$ A recent study from Thailand reported an incidence of 152.9/100,000 population ${ }^{2}$ and data from East Malaysia (State of Sabah), available only in abstract, reported an incidence of 72/100,000 population. ${ }^{3}$ Reports from two tertiary hospitals in central Peninsular Malaysia indicated an overall low prevalence of non-variceal upper GI bleeding among the ethnic Malays. ${ }^{4-6}$

There is a reducing trend of peptic ulcer disease observed within Asia, and this is largely a result of reducing prevalence of $H$. pylori infection. This trend is likely to continue into the future and a time will come when $H$. pylori joins the ranks of smallpox and polio. ${ }^{7}$ The population in the north-eastern region of Peninsular Malaysia (state of Kelantan), that consists of $90 \%$ ethnic Malays, had a seroprevalence of Helicobacter pylori ( $H$. pylori) infection of only $4.2 \%$ among 496 blood donors and 4.8\% among 921 patients attending a health screening clinic. ${ }^{8}$ The $H$. pylori infection rate reported from gastric biopsies was $20 \%$ in duodenal ulcer, $21.2 \%$ in gastric ulcer, $16.7 \%$ in duodenal erosion and $17.1 \%$ in gastric erosion. ${ }^{9}$ The incidence of peptic ulcer perforations within the region from 1991 to 92 was only 1.5/100,000 person-years. ${ }^{8}$

The exceptional low prevalence of $H$. pylori in the population from north-eastern region of Peninsular Malaysia provides us with an opportunity to contemplate the future without the 
infection. Our study aimed to determine the risk and clinical outcomes of acute non-variceal upper GI bleeding in this population with a low prevalence of $H$. pylori infection. The association between clinical characteristics, risk factors and treatment given with risk and bleeding outcomes was also assessed.

\section{METHODS}

\section{Study population}

We reviewed and analysed all prospective cases with a diagnosis of GI bleeding between 2003 and 2006 in our GI registry database. Cases were admitted into a tertiary university hospital (Hospital Universiti Sains Malaysia) situated in the north-eastern region of Peninsular Malaysia (State of Kelantan). The region consisted of 0.7 to 0.8 million of population (2003 - 2006) with a diverse racial background but has a predominant Malay population of approximately $90 \%$.

All adults above 18 years old with upper GI bleeding as a diagnosis in the GI registry were then screened for inclusion. Subjects with typical symptoms and signs and subsequently requiring upper endoscopy after informed consent and confirmed to have non-variceal causes of acute upper GI bleeding were then included into the analysis. Upper endoscopy was performed in all cases within 24 hour upon admission. H. pylori status, where available, as detected by either a rapid urease test (CLOtest ${ }^{\circledR}$, Kimberly-Clark, Roswell, USA) and or histology from biopsies taken during endoscopy, would also be recorded. Exclusion criteria included those patients with lower GI bleeding, variceal bleeding, bleeding due to underlying hematologic disorders, GI bleeding of unknown origin, and those patients who did not have an endoscopy examination.

The study was approved by the Human Ethics Committee of Universiti Sains Malaysia.

\section{Study outcome and definitions}

Rockall score ${ }^{10}$ was utilised to classify study population into low risk (score $\leq 5$ ) and high risk (score $>5)^{11}$ for non-variceal upper GI bleeding. Briefly, Rockall score is made up of five variables, three of which are clinical parameters (age, shock and co-morbidities) and the other two endoscopic features (causative lesions and stigmata of recent haemorrhage). ${ }^{10,12}$ Each variable can be scored between 0 and 3, with a maximum score of 15 for all 5 variables.

The primary study outcome was to determine risk, based upon the Rockall score, of inhospital mortality, recurrent bleeding and the need for surgery in this population with non- 
variceal upper GI bleeding. Clinical characteristics, risk factors, endoscopic features and endoscopic treatment given were also assessed for their association with study outcomes.

In-hospital mortality was defined as death during the period of hospital stay which was directly associated with upper GI bleeding and this was compared to patients still alive after 30 days. Recurrent bleeding was defined as new episode of bleeding during the period of hospital stay after index bleeding had stopped, manifested as recurrence of symptoms and signs (fresh blood in nasogastric aspirate) of bleeding and this was compared to those without bleeding after index event. The need for surgery was defined as the need to undergo laparotomy after failure of endoscopy interventions to stop bleeding and this was compared to those patients not needing any surgical interventions after index bleed.

\section{Data and statistical analysis}

Data were presented in frequency and percentages unless otherwise stated. Statistical analysis was performed with SPSS version 19.0 (SPSS Inc., Chicago, IL, USA). Univariable and multivariable analyses were used to test the association between variables. Receiver operating characteristics (ROC) curve was utilised to determine the usefulness of Rockall score in predicting the primary outcomes in this study population. A $P$ value of $<0.05$ was considered statistically significant for all analyses.

\section{RESULTS}

\section{Incidence of upper GI bleeding and study population characteristics}

During the study period between 2003 and 2006, a total of 742 patients (incidence 6.5/100,000 person-years) were registered in the database with a diagnosis of GI bleeding. Of 742 patients, 250 patients $(2.2 / 100,000$ person-years) were subsequently identified and confirmed to have nonvariceal upper GI bleeding. The incidence of non-variceal bleeding was relatively similar between gender with 1.3/100,000 person-years in men and 1/100,000 person-years in women. Peptic ulcer bleeding was the primary aetiology of non-variceal bleeding in 204 patients $(1.8 / 100,000$ person-years or $81.6 \%$ of total cases), of which $54 \%$ of cases were due to gastric ulcer bleeding (Table 1). Only 2 patients were H. pylori positive and both patients were of nonMalays in origin. The mean age of 250 patients was 62.1 years (range $15-97$ years) with older patients, at a mean age of 68.5 years, tended to have a higher risk score $(P=0.01)$. 


\section{Primary outcome}

Majority of patients were of low risk on admission with $85.2 \%(213 / 250)$ of patients had a Rockall score $\leq 5$ and a mean Rockall score of 4.4. There were 3.6\% (9/250) in-hospital mortality, 9.6\% (24/250) recurrent bleed and 4.0\% (10/250) of patients who subsequently required surgery. A higher Rockall score in this population was associated with increased inhospital mortality (mean score 7.0, $P<0.001$ ), recurrent bleeding (mean score 5.1, $P=0.01$ ) and need for surgery (mean score $4.8, P=0.01$ ). A Rockall score $>5$ was significant in predicting recurrent bleeding in this population but only with area under curve or AUC of 0.6 (95\% CI: 0.5 $0.7, P=0.04)$ (Figure 1).

\section{Clinical features, co-morbidities and other risk factors (Table 1)}

Peptic ulcer bleeding was more likely to re-bleed $(P=0.04)$ during hospitalisation (Table 1). Duodenal ulcers (DU) were more likely to occur in the elderly (mean 66.2 years, $P=0.04$ ) but no difference in age was noted with gastric ulcers (GU) (mean 61.1 years with gastric ulcers vs. 63.2 years without gastric ulcers, $P=0.3$ ). DUs, but not GUs or gastroduodenal ulcers/erosions, were associated with a higher risk score, mortality, recurrent bleeding and need for surgery (all $P<$ $0.05)$.

Symptoms of anaemia were associated with risk of recurrent bleeding $(P=0.002)$ and need for surgery $(P=0.02)$. Epigastric pain was associated with increased need for surgery $(P=$ 0.005). A low hemoglobin level was associated with a higher risk score, in-hospital mortality, recurrent bleeding and need for surgery (all $P<0.05$ ). Recurrent bleeding was more common in those patients with a raised urea $(P=0.03)$ and creatinine $(P=0.03)$. A raised urea was also more likely to be associated with in-hospital mortality $(P=0.04)$.

Both chronic liver disease and septicaemia were significantly associated with increased inhospital mortality and recurrent bleeding (all $P<0.05$ ) (Table 1). History of previous peptic ulcer disease was associated with a higher risk score on admission $(P=0.02)$. More than $1 / 3$ of patients had reported NSAIDs use but on its own, it was not associated with any of the studied outcomes on univariate analysis (Table 1). Aspirin use alone was associated with recurrent bleeding $(P=$ $0.02)$ but warfarin use alone was associated in-hospital mortality $(P=0.02)$ (Table 1).

\section{Endoscopic features and treatment (Table 2)}

Major stigmata of recent hemorrhage (SRH) were present in $26 \%$ of all bleeding and their presence were associated with a higher risk score, in-hospital mortality, recurrent bleeding and 
need for surgery (all $P<0.05$ ) (Table 2). More than half were Forrest III lesions $(57.2 \%)$ and GUs rather than DUs were frequently Forrest III (41.2\% vs. $8.4 \%)$. However, only Forrest III DUs were associated with recurrent bleeding $(P=0.04)$. DUs were also more likely than GUs to have Forrest I lesions (6.8\% vs. 3.6\%). Likewise, DUs rather than GUs were associated with a higher risk score, mortality, recurrent bleeding and need for surgery (all $P<0.05$ ). GUs were more common than DUs to have Forrest II lesions (9.6\% vs. 4.4\%) but both were associated with a higher risk score (both $P=0.01$ ).

All patients admitted with upper GI bleeding had received PPI but there was no difference in studied outcomes between omeprazole and pantoprazole (Table 2). Blood transfusion was needed in $76 \%$ of all bleeding and its requirement was associated with risk of recurrent bleeding $(P=$ 0.001). Endoscopic interventions were employed in $38.4 \%$ of all bleeding, with a third of these were being performed in high risk patients (Table 2). Of all patients with bleeding, adrenaline was the sole intervention in $17.2 \%$, adrenaline with coagulation in $13.2 \%$ and adrenaline with clip in $8 \%$. Use of adrenaline only was associated with a higher risk score, recurrent bleeding and need for surgery (all $P<0.001$ ). Likewise, adrenaline with clip therapy was associated with a higher risk score, recurrent bleeding and need for surgery (all $P<0.005$ ). Adrenaline with coagulation therapy was associated with recurrent bleeding $(P=0.02)$ and need for surgery $(P=$ $0.005)$.

\section{Multivariable analysis (Table 3)}

Of the variables associated with a high Rockall score, major SRH was the factor most predictive of high risk in this population (OR 25.2, 95\% CI 8.5-74.3) (Table 3). This variable was also associated with increased in-hospital mortality (OR 11.0, 95\% CI 1.9 - 62.1). Likewise, septicaemia was associated with a high risk score (OR 15.4, 95\% CI: 2.9 - 81.1) and in-hospital mortality (OR 27.1, 95\% CI: 4.5-162.8). Warfarin use was the other risk factor associated with inhospital mortality (OR 16.7, 95\% CI 2.1 - 132.5). Use of adrenaline only during endoscopic intervention was the factor most associated with increased risk of recurrent bleeding (OR 4.4, 95\% CI: 1.5-12.7) and need for surgery (OR 9.8, 95\% CI: 2.3-43.9). Another factor associated with recurrent bleeding was a raised creatinine (OR 1.002, 95\% CI: 1.0-1.004). Epigastric pain was highly predictive for increased need of surgery in this population (OR 6.3, 95\% CI 1.2-32.2).

\section{DISCUSSION}


In this population starting with an exceptionally low prevalence of $H$. pylori infection, the incidence of 2.2/100,000 person-years of non-variceal upper GI bleeding was also notably low.

177 Peptic ulcer bleeding was the most common cause with an incidence of 1.8/100,000 person-years and this was almost similar to previously reported peptic ulcer perforation of 1.5/100,000 personyears. ${ }^{8}$ Elderly in this population were more susceptible to non-variceal bleeding, especially from DUs and had a higher risk score and concomitant co-morbidities, in keeping with recent observation in $H$. pylori-eradicated populations. ${ }^{13}$

Rockall score $>5$ had been shown to be useful in predicting recurrent bleeding in our population but the AUC result suggests that it may be less satisfactory. This might be related to the threshold of 5 that was initially chosen in the current study. Since many patients admitted to referral institutions were likely to have high risk endoscopic features (stigmata of recent bleed) therefore a threshold of 5 seems reasonable in order to discriminate high risk from the low risk patients, as previously reported. ${ }^{11,14}$ However, our results reported a lower rate of high risk features, which would then have resulted in a less accurate AUC. Hence, a threshold below 5 may have been preferable in our population and this merits further analysis. A number of recent studies have similarly questioned the accuracy of Rockall scores in different populations and settings. ${ }^{15,16}$ Further prospective studies are needed to verify their findings.

Our study shared similar baseline characteristics with Vreeburg et al. ${ }^{13}$ including definition for mortality but our results suggest a better prediction of recurrent bleeding rather than inhospital death. A higher rate of recurrent bleeding observed in our population as compared to inhospital mortality might explain this discrepancy. The low hemoglobin and urea levels indicate a minor bleeding risk in general, compatible with the overall low risk score observed in this population. The generally low risk score in this population would not, however, allow one to decide for the need of therapeutic endoscopy. Blatchford score may have been more useful in this regard. $^{18}$

Among the variables described in Rockall score, SRH stood out as the most predictive of high risk and in-hospital mortality. The presence of $\mathrm{SRH}$ is of greater significance in $\mathrm{H}$. pyloriassociated bleeding GUs than DUs. ${ }^{19}$ In our study population, more than half of upper GI bleeding was a result of GUs with only $20 \%$ due to DUs. However, GUs were more likely Forrest III lesions (57.2\%) but had relatively benign outcomes. In contrast, DUs, while less common, and were more likely Forrest I and II lesions, but there was significant associations between DUs with all studied outcomes. Previous studies have also similarly observed that $H$. pylori-negative DUs were more likely to bleed and were more common among the elderly population with risk 
208 factors. $^{20,21}$ These studies were limited by false negative results for $H$. pylori, but our study 209 population did not suffer from this limitation. ${ }^{20}$

210 Septicaemia, while not a variable in the Rockall score, was also highly predictive of high risk 211 and in-hospital mortality, similarly reported by Zimmerman and others. ${ }^{22,23}$ In the original Rockall 212 validation study, pneumonia which was associated with septicaemia, was included in the model 213 but not in the complete model. ${ }^{10}$ Our study suggests that septicaemia, if present, should be 214 considered as a major co-morbidity and should be given a score of 2 . An elevated creatinine was 215 predictive of increased risk of recurrent bleeding in the multivariable analysis, in agreement with 216 Zuckerman and others ${ }^{24,25}$ Patients with ischemic heart disease, the most common co-morbidity in our study, were also frequently impaired in their renal function. ${ }^{26}$

Non-variceal upper GI bleeding was associated with more adverse outcomes in the current study with a mostly elderly population, and an almost absence of $H$. pylori infection, and in the presence of offending agents including aspirin, NSAIDs and warfarin. In a study from Japan, the usage of aspirin and NSAIDs was not associated with a serious outcome in GU bleeding ${ }^{27}$ but the role of $H$. pylori infection was not addressed. Recent studies found that patients with H. pylorinegative peptic ulcers and who took aspirin were more likely to have a higher bleeding risk. ${ }^{28-30}$ NSAIDs and aspirin in combination, rather in isolation, would have produced the greatest risk, and this might explain why our multivariate analysis did not have any association. ${ }^{31,32}$ Further studies are needed to determine the significance of our findings since these results may have a long term impact in the $H$. pylori-eradicated populations.

Endoscopic interventions were carried out in only a third of patients with high risk scores and this implied that Rockall score is not useful in selecting patients who require interventions. Endoscopic therapy with adrenaline only was associated with a four-fold risk for recurrent bleeding and a ten-fold risk for surgical intervention based on the multivariable analysis; figures that were similar to Levin et al. ${ }^{33}$ This indicates that adrenaline alone is unlikely to be sufficient when endoscopic interventions are needed and is not in line with our current practice or guidelines..$^{34,35}$

The need for surgery was not an outcome initially included during the validation study of Rockall score, however surgical intervention is frequently sought in the setting of failed endoscopic therapies. In the current study, the need for surgical intervention of $4.0 \%$ was relatively similar to the rate of in-hospital mortality of 3.6\%. Previous study indicated an overall mortality of $34.1 \%$ in patients with upper GI bleeding requiring surgery. ${ }^{36}$ Epigastric pain, predictive of the need of surgery, may be a sign of impending perforation, and should be carefully 
241

242

243

244

245

246

247

248

249

250

251

252

253

254

255

256

257

258

259

260

261

262

assessed especially in this largely rural-majority population who often present late in their course of disease.

Study limitations should be mentioned. There was only one other centre in the region managing upper GI bleeding, and this might affect our incidence calculation slightly but our institution is a primary referral institution with a reliable GI database. The rate of $H$. pylori infection was underestimated in this study for several reasons. One was the use of rapid urease test, which had been shown to be unreliable during the acute phase of ulcer bleeding. ${ }^{37,38}$ Due to this reason, based on the discretion of the managing endoscopist, only $35.6 \%$ of patients were tested. Of those tested negative with the urease test, histology was reliable in confirming the absence of $H$. pylori without other additional tests. On the other hand, this limitation on $H$. pylori would not have affected our current study since we have already published extensively on the exceptional low prevalence of $H$. pylori in the region. ${ }^{6,8,9}$

So what would be the future in patients having non-variceal upper GI bleeding in the absence of H. pylori? We can conclude that based on our population with an exceptional low prevalence of H. pylori infection and also peptic ulcer disease, acute non-variceal upper GI bleeding is also of low incidence, similar to peptic ulcer perforation rates. An absence of H. pylori infection may not however reduce the risk of peptic ulcer bleeding in the presence of risk factors especially offending drugs in an elderly population.

\section{ACKNOWLEDGEMENT}

We would like to thank Universiti Sains Malaysia for the incentive grant in 2007. We are grateful to Professor David Graham from the Baylor College of Medicine, Houston, Texas for his valuable comments to the paper.

\section{REFERENCES}

1. Sung JJ, Chan FK, Chen M, Ching JY, Ho KY, Kachintorn U, Kim N, Lau JY, Menon J, Rani AA, Reddy N, Sollano J, Sugano K, Tsoi KK, Wu CY, Yeomans N, Vakil N, Goh KL; Asia-Pacific Working Group. Asia-Pacific Working Group consensus on non-variceal upper gastrointestinal bleeding. Gut 2011; 60: 1170-7.

2. Sangchan A, Sawadpanitch K, Mairiang P, Chunlertrith K, Sukeepaisarnjaroen W, Sutra S, Thavornpitak Y. Hospitalized incidence and outcomes of upper 
gastrointestinal bleeding in Thailand. J Med Assoc Thai 2012; 95 Suppl 7: S190-5.

3. Cheng JLS, Gunn A, Menon J, Arokiasamy J, Ong P, Loong SY, Oommen G, Damodaran A. Aetiology of acute upper gastrointestinal bleeding in East Malaysia. Med J Malaysia 2001; 56 (supp A): D31.

4. Lim TM, Lu PY, Meheshinder S, Selvindoss P, Balasingh D, Ramesh J, Qureshi A. An audit of upper gastrointestinal bleeding at Seremban Hospital. Med J Malaysia 2003; 58: 522-5.

5. Lakhwani MN, Ismail AR, Barras CD, Tan WJ. Upper gastrointestinal bleeding in Kuala Lumpur Hospital, Malaysia. Med J Malaysia 2000; 55: 498-505.

6. Lee YY, Mahendra Raj S, Graham DY. Helicobacter pylori infection - A boon or a bane: lessons from studies in a low prevalence population. Helicobacter 2013; 18 : $338-46$.

7. Graham DY, Yamaoka Y, Malaty HM. Contemplating the future without Helicobacter pylori and the dire consequences hypothesis. Helicobacter 2007; 12 Suppl 2: 64-8.

8. Uyub AM, Raj SM, Visvanathan R, Nazim M, Aiyar S, Anuar AK, Mansur M. Helicobacter pylori infection in north-eastern peninsular Malaysia. Evidence for an unusually low prevalence. Scand J Gastroenterol 1994; 29: 209-213.

9. Raj SM, Yap K, Haq JA, Singh S, Hamid A. Further evidence for an exceptionally low prevalence of Helicobacter pylori infection among peptic ulcer patients in north-eastern peninsular Malaysia. Trans R Soc Trop Med Hyg 2001; 95: 24-7.

10 Rockall TA, Logan RFA, Devlin HB, Northfield TC. Risk assessment after acute upper gastrointestinal haemorrhage. Gut 1996; 38: 316-21.

11. Bessa X, O’Callaghan E, Balleste B, Nieto M, Seoane A, Panades A, Vazquez DJ, Andreu M, Bory F. Applicability of the Rockall score in patients undergoing endoscopic therapy for upper gastrointestinal bleeding. Dig Liver Dis 2006; 38: $12-7$.

12 Forrest JA, Finlayson ND, Shearman DJ. Endoscopy in gastrointestinal bleeding. . Lancet 1974; 2: 394-7.

13 Domon K, Hirano N, Otsuka T, Fujitsuka Y, takeuchi M, Kikuchi Y, Nakano S, Igarashi Y. Clinical evaluation of hemorrhagic gastroduodenal ulcer in the elderly: 
is Helicobacter pylori infection a risk factor for haemorrhage? Dig Endosc 2012; 25: 319-24.

14 Camellini L, Merighi A, Pagnini C, Azzolini F, Guazetti S, Scarcelli A, Manenti F,

- Rigo GP. Comparison of three different risk scoring systems in non-variceal upper gastrointestinal bleeding. Dig Liver Dis 2004; 36: 271-7.

15 Wang CY, Qin J, Wang J, Sun CY, Cao T, Zhu DD. Rockall score in predicting outcomes of elderly patients with acute upper gastrointestinal bleeding. World $\mathrm{J}$ Gastroenterol 2013; 19: 3466-72.

16 Custódio Lima J, Garcia Montes C, Kibune Nagasako C, Soares Ruppert Reis GF, - Meirelles Dos Santos JO, Guerrazzi F, Mesquita MA. Performance of the Rockall scoring system in predicting the need for intervention and outcomes in patients with nonvariceal upper gastrointestinal bleeding in a Brazilian setting: a prospective study. Digestion 2013: 88: 252-7.

17 Vreeburg EM, Terwee CB, Snel P, Rauws EA, Bartelsman JF, Meulen JH, Tytgat - GN. Validation of the Rockall risk scoring system in upper gastrointestinal bleeding. Gut 1999; 44: 331-5.

18 Pang SH, Ching JY, Lau JY, Sung JJ, Graham DY, Chan FK. Comparing the Blatchford and pre-endoscopic Rockall score in predicting the need for endoscopic therapy in patients with upper GI haemorrhage. Gastrointest Endosc 2010; 71: $1134-40$.

19 Chang-Chien CS, Wu CS, Chen PC, Lin DY, Chu CM, Fang KM, Sheen IS, Liaw

- YF. Different implications of stigmata of recent haemorrhage in gastric and duodenal ulcers. Dig Dis Sci 1988; 33: 400-4.

20 Gisbert JP, Calvet X. Review article: Helicobacter pylori-negative duodenal ulcer disease. Aliment Pharmacol Ther 2009; 30: 791-815.

21 Chu KM, Kwok KF, Law S, Wong KH. Patients with Helicobacter pylori positive . and negative duodenal ulcers have distinct clinical characteristics. World $J$ Gastroenterol 2005; 11: 3518-22.

22 Zimmerman J, Meroz Y, Arnon R, Tsvang E, Siguencia J. Predictors of mortality . in hospitalized patients with secondary upper gastrointestinal haemorrhage. $J$ Intern Med 1995; 237: 331-7. 
23 Afessa B. Systemic inflammatory response syndrome in patients hospitalized for - gastrointestinal bleeding. Crit Care Med 1999; 27: 554-7.

24 Zuckermann GR, Cornette GL, Clouse RE, Harter HR. Upper gastrointestinal . bleeding in patients with chronic renal failure. Ann Intern Med 1985; 102: 588-92.

25 Sood P, Kumar G, Nanchal R, Sakhuja A, Ahmad S, Ali M, Kumar N, Ross EA.

- Chronic kidney disease and end-stage renal disease predict higher risk of mortality in patients with primary upper gastrointestinal bleeding. Am J Nephrol 2012; 35: 216-24.

26 Shalev A, Zahger D, Novack V, Etzion O, Shimony A, Gilutz H, Cafri C, Ilia R, - Fich A. Incidence, predictors and outcome of upper gastrointestinal bleeding in patients with acute coronary syndromes. Int J Cardiol 2012; 157: 386-90.

27 Ishikawa S, Inaba T, Mizuno M, Okada H, Kuwaki K, Kuzuma T, Yokota H, - Fukuda Y, Takeda K, Nagano H, Wato M, Kawai K. Incidence of serious gastrointestinal bleeding in patients taking non-steroidal anti-inflammatory drugs in Japan. Acta Med Okayama 2008; 62: 29-36.

28 Kang JM, Kim N, Lee BH, Park HK, Jo HJ, Shin CM, Lee SH, Park YS, Hwang - JH, Kim JW, Jeong SH, Lee DH, Jung HC, Song IS. Risk factors for peptic ulcer bleeding in terms of Helicobacter pylori, NSAIDs and antiplatelet agents. Scand $J$ Gastroenterol 2011; 46: 1295-301.

29 Chan FK, Ching JY, Suen BY, Tse YK, Wu JC, Sung JJ. Effects of Helicobacter - pylori infection on long -term risk of peptic ulcer bleeding in low-dose aspirin users. Gastroenterology 2013; 144: 528-35.

30 Hernandez-Diaz S, Garcia Rodriquez LA. Cardioprotective aspirin users and their excess risk of upper gastrointestinal complications. BMC Med 2006; 4: 22.

31 Hreinsson JP, Kalaitzakis E, Gudmundsson S, Bjornsson ES. Upper gastrointestinal bleeding: incidence, etiology and outcomes in a population-based setting. Scand J Gastroenterol 2013; 48: 439-47.

32 Lee YY, Noridah N. Non-variceal upper gastrointestinal bleeding: is it all about comorbidities. Gastroenterology 2013; 145: 1495-96.

33 Levin DA, Watermeyer GA, Deetleefs E, Metz DC, Thomson SR. The efficacy of endoscopic therapy in bleeding peptic ulcer patients. S Afr Med J 2012; 102: 290- 
3.

34 Chung SS, Lau JY, Sung JJ, Chan AC, Lai CW, Ng EK, Chan FK, Yung MY, Li

- AK. Randomised comparison between adrenaline injection alone and adrenaline injection plus heat probe treatment for actively bleeding ulcers. $B M J 1997 ; 314$ : 1307-11.

35 Chung IK, Ham JS, Kim HS, Park SH, Lee MH, Kim SJ. Comparison of the hemostatic efficacy of the endoscopic hemoclip method with hypertonic salineepinephrine injection and a combination of the two for the management of bleeding peptic ulcers. Gastrointest Endosc 1999; 49: 13-8.

36 Czymek R, Großmann A, Roblick U, Schmidt A, Fischer F, Bruch HP, Hildebrand - P. Surgical management of acute upper gastrointestinal bleeding: still a major challenge. Hepatogastroenterology 2012; 59: 768-73.

37 Schilling D, Demel A, Adamek HE, Nusse T, Weldmann E, Riemann JF. A - negative rapid urease test is unreliable for exclusion of Helicobacter pylori infection during the acute phase of ulcer bleeding. A prospective case control study. Dig Liver Dis 2003; 35: 217-21.

38 Lee JM, Breslin NP, Fallon C, O’Morain CA. Rapid urease tests lack sensitivity in - Helicobacter pylori diagnosis when peptic ulcer disease presents with bleeding. Am J Gastroentero 2000; 95: 1166-70.

Figure 1: The usefulness of Rockall score in predicting outcomes in non-variceal upper 266 gastrointestinal bleeding in this ethnic Malay-majority population 


\section{Table 1 (on next page)}

Clinical characteristics of study population

n; frequency, SEM; standard error of mean, \# significant $\mathrm{P}$ value $<0.05$ (Fisher's exact or Pearson Chi-Square test for categorical and t-test for continuous variables) 
Table 1: Clinical characteristics of study population

\begin{tabular}{|c|c|c|c|c|c|}
\hline Parameters & All & High risk & Mortality & $\begin{array}{l}\text { Recurrent } \\
\text { bleeding }\end{array}$ & $\begin{array}{l}\text { Need for } \\
\text { surgery }\end{array}$ \\
\hline Age, years, mean (SEM) & $62.1(1.0)$ & $68.5(2.6)^{\#}$ & $60.5(7.4)$ & $60.5(3.4)$ & $62.4(4.5)$ \\
\hline \multicolumn{6}{|l|}{ Gender, $\mathrm{n}(\%)$} \\
\hline Male & $144(57.6)$ & $20(8.0)$ & $5(2.0)$ & $17(6.8)$ & $8(3.2)$ \\
\hline Female & $106(42.4)$ & $17(6.8)$ & $4(1.6)$ & $7(2.8)$ & $2(0.8)$ \\
\hline \multicolumn{6}{|l|}{ Ethnic, n (\%) } \\
\hline 2 Malays & $209(83.6)$ & $31(12.4)$ & $7(2.8)$ & $22(8.8)$ & $11(100)$ \\
\hline Non-Malays & $41(16.4)$ & $6(2.4)$ & $2(0.8)$ & $2(0.8)$ & 0 \\
\hline \multicolumn{6}{|l|}{ DCausative lesions, n (\%) } \\
\hline Peptic Ulcer & 204 (81.6) & $32(12.8)$ & $9(3.6)$ & $24(9.6)^{*}$ & $10(4.0)$ \\
\hline Gastric ulcer & $135(54.0)$ & $15(6.0)$ & $3(1.2)$ & $10(4.0)$ & $4(1.6)$ \\
\hline Duodenal ulcer & $49(19.6)$ & $17(6.8)^{\#}$ & $6(2.4)^{\#}$ & $14(5.6)^{*}$ & $6(2.4)^{\#}$ \\
\hline Gastroduodenal ulcers/erosions & $20(8.0)$ & 0 & 0 & 0 & 0 \\
\hline Gastroduodenitis & $36(14.4)$ & $4(1.6)$ & 0 & 0 & 0 \\
\hline Others (tumours, telangiectasia) & $10(4.0)$ & $1(0.4)$ & 0 & 0 & 0 \\
\hline \multicolumn{6}{|l|}{ Presenting symptoms, $\mathrm{n}(\%)$} \\
\hline Melaena & $189(75.6)$ & $32(12.8)$ & $6(2.4)$ & $22(8.8)$ & $11(4.4)$ \\
\hline Haematemesis & $117(46.8)$ & $16(6.4)$ & $4(1.6)$ & $9(3.6)$ & $3(1.2)$ \\
\hline Epigastric pain & $103(41.2)$ & $16(6.4)$ & $2(0.8)$ & $11(4.4)$ & $9(3.6)^{\#}$ \\
\hline Anaemia & $168(67.2)$ & $30(12.0)^{\#}$ & $8(3.2)$ & $23(9.2)^{*}$ & $11(4.4)^{*}$ \\
\hline \multicolumn{6}{|l|}{ Laboratory parameters, mean (SEM) } \\
\hline Hemoglobin $(\mathrm{g} / \mathrm{dl})$ & $8.2(0.2)$ & $7.3(0.4)^{\#}$ & $6.5(0.7)^{*}$ & $6.7(0.3)^{*}$ & $6.3(0.4)^{*}$ \\
\hline Platelet $\left(\times 10^{3} / \mathrm{mm}^{3}\right)$ & $292.3(10.4)$ & $261.9(25.3)$ & $248.9(43.1)$ & $339.7(50.4)$ & $375(51.4)$ \\
\hline INR & $1.3(0.05)$ & $1.4(0.1)$ & $2.0(0.4)$ & $1.4(0.1)$ & $1.3(0.1)$ \\
\hline aPTT (seconds) & $33.9(0.8)$ & $37.9(1.6)^{\#}$ & $39.9(4.2)$ & $38.8(3.3)$ & $35.4(2.2)$ \\
\hline Urea $(\mathrm{mmol} / \mathrm{l})$ & $14.1(0.8)$ & $18.3(2.4)$ & $22.5(4.5)^{\#}$ & $21.0(3.2)^{\#}$ & $20.3(4.4)$ \\
\hline Creatinine (mmol/l) & $170.9(13.6)$ & $196.3(35.1)$ & $316.9(96.4)$ & $290.4(54.4)^{\#}$ & $217.8(54.1)$ \\
\hline \multicolumn{6}{|l|}{ Co-morbidities, n (\%) } \\
\hline Ischemic heart disease & $53(21.2)$ & $14(5.6)^{\#}$ & $2(0.8)$ & $1(0.4)$ & 0 \\
\hline Chronic renal failure & $41(16.4)$ & $12(4.8)^{*}$ & $2(0.8)$ & $7(2.8)$ & $3(1.2)$ \\
\hline Chronic liver disease & $11(4.4)$ & $4(1.6)^{\#}$ & $2(0.8)^{\#}$ & $3(1.2)^{\#}$ & $1(0.4)$ \\
\hline Diabetes Mellitus & $59(23.6)$ & $11(4.4)$ & $4(1.6)$ & $8(3.2)$ & $3(1.2)$ \\
\hline Malignancies & $17(6.8)$ & $1(0.4)$ & $4(1.6)$ & $4(1.6)$ & $1(0.4)$ \\
\hline Septicaemia & $12(4.8)$ & $6(2.4)^{\#}$ & $4(1.6)^{\#}$ & $4(1.6)^{\#}$ & $1(0.4)$ \\
\hline \multicolumn{6}{|l|}{ Risk factors, $\mathrm{n}(\%)$} \\
\hline Previous peptic ulcer disease & $41(16.4)$ & $11(4.4)^{\sharp}$ & $1(0.4)$ & $6(2.4)$ & $2(0.8)$ \\
\hline NSAIDs & $85(34.0)$ & $12(4.8)$ & $3(1.2)$ & $11(4.4)$ & $5(2.0)$ \\
\hline Aspirin & $57(22.8)$ & $9(3.6)$ & $2(0.8)$ & $1(0.4)^{\#}$ & 0 \\
\hline Clopidogrel & $23(9.2)$ & $6(2.4)$ & $1(0.4)$ & 0 & 0 \\
\hline Warfarin & $13(5.2)$ & $4(1.6)$ & $2(0.8)^{\#}$ & 0 & 0 \\
\hline Corticosteroids & $10(4.0)$ & $1(0.4)$ & 0 & $2(0.8)$ & $1(0.4)$ \\
\hline Herbs/traditional medicine & $4(1.6)$ & $2(0.8)$ & 0 & 0 & 0 \\
\hline
\end{tabular}

Legend: n; frequency, SEM; standard error of mean, \# significant $P$ value $<0.05$ (Fisher's exact or Pearson Chi-Square test for categorical and t-test for continuous variables) 


\section{Table 2 (on next page)}

Endoscopic features and treatments given

$\mathrm{n}$; frequency, \# significant P value $<0.05$ (Fisher's exact test or Pearson Chi-Square test for categorical and t-test for continuous variables) 
Table 2: Endoscopic features and treatment given

\begin{tabular}{|c|c|c|c|c|c|}
\hline Parameters & All & High risk & Mortality & $\begin{array}{l}\text { Recurrent } \\
\text { bleeding }\end{array}$ & $\begin{array}{l}\text { Need for } \\
\text { surgery }\end{array}$ \\
\hline \multicolumn{6}{|l|}{ Stigmata of recent haemorrhage, $n(\%)$} \\
\hline None or dark spots & $185(74.0)$ & $9(3.6)$ & $2(0.8)$ & $10(4.0)$ & $3(1.2)$ \\
\hline Major stigmata & $65(26.0)$ & $28(11.2)^{\#}$ & $7(2.8)^{\#}$ & $14(6.4)^{\#}$ & $7(2.8)^{\#}$ \\
\hline \multicolumn{6}{|l|}{ Forrest classification, n (\%) } \\
\hline Forrest I (a: spurting, b: oozing) & $26(10.4)$ & $13(5.2)^{\#}$ & $5(2.0)^{\#}$ & $11(4.4)^{\#}$ & $6(2.4)^{\#}$ \\
\hline Gastric ulcer & $9(3.6)$ & $3(1.2)$ & $1(0.4)$ & $3(1.2)$ & $3(1.2)$ \\
\hline Duodenal ulcer & $17(6.8)$ & $10(4.0)^{\#}$ & $4(1.6)^{\#}$ & $8(3.2)^{\#}$ & $3(1.2)^{\#}$ \\
\hline Forrest II (a: vessel, b: clot, c: haematin) & $35(14.0)$ & $13(5.2)^{\#}$ & $1(0.4)$ & $3(1.2)$ & $2(0.8)$ \\
\hline Gastric ulcer & $24(9.6)$ & $8(3.2)^{\#}$ & 0 & $2(0.8)$ & $1(0.4)$ \\
\hline Duodenal ulcer & $11(4.4)$ & $5(2.0)^{\#}$ & $1(0.4)$ & $1(0.4)$ & $1(0.4)$ \\
\hline Gastroduodenal ulcers & $1(0.4)$ & 0 & 0 & 0 & 0 \\
\hline Forrest III (clean base) & $143(57.2)$ & $2(0.8)$ & $1(0.4)$ & $5(2.0)$ & $2(0.8)$ \\
\hline Gastric ulcer & $103(41.2)$ & $4(1.6)^{\#}$ & $2(0.8)$ & $5(2.0)$ & 0 \\
\hline Duodenal ulcer & $21(8.4)$ & $2(0.8)$ & $1(0.4)$ & $5(2.0)^{\#}$ & $2(0.8)$ \\
\hline Gastroduodenal ulcers & $19(7.6)$ & 0 & 0 & 0 & 0 \\
\hline \multicolumn{6}{|l|}{ Type of PPI, n (\%) } \\
\hline Omeprazole & $42(16.8)$ & $6(2.4)$ & 0 & $2(0.8)$ & 0 \\
\hline Pantoprazole & $208(83.2)$ & $31(12.4)$ & $9(3.6)$ & $22(8.8)$ & $10(4.0)$ \\
\hline \multicolumn{6}{|l|}{ Tranfusion requirement, $\mathrm{n}(\%)$} \\
\hline Yes & $190(76.0)$ & $32(12.8)$ & $9(3.6)$ & $24(9.6)^{\#}$ & $10(4.0)$ \\
\hline No & $60(24.0)$ & $5(2.0)$ & 0 & 0 & 0 \\
\hline \multicolumn{6}{|l|}{ Endoscopic intervention, $\mathrm{n}(\%)$} \\
\hline Adrenaline only & $43(17.2)$ & $14(5.6)^{\#}$ & $4(1.6)$ & $12(4.8)^{\#}$ & $7(2.8)^{\#}$ \\
\hline+ coagulation & $33(13.2)$ & $7(2.8)$ & $2(0.8)$ & $7(2.8)^{\#}$ & $5(2.0)^{\#}$ \\
\hline+ clip & $20(8.0)$ & $10(4.0)^{\#}$ & 0 & $8(3.2)^{\#}$ & $4(1.6)^{\#}$ \\
\hline
\end{tabular}

Legend: n; frequency, \# significant $P$ value $<0.05$ (Fisher's exact test or Pearson Chi-Square test for categorical and t-test for continuous variables) 


\section{Table 3 (on next page)}

Results of multiple logistic regression analysis (forward: LR)

LR; likelihood ratio, OR; adjusted odd ratio, $\mathrm{Cl}$; confidence interval 
Table 3: Results of multiple logistic regression analysis (forward: LR)

\begin{tabular}{|lccc|}
\hline \multicolumn{1}{|l}{ Outcome and risk factors } & OR & $\mathbf{9 5 \%}$ CI for OR & P value \\
High risk & & & \\
$\quad$ Major stigmata of bleeding & 25.2 & $8.5-74.3$ & $<0.001$ \\
$\quad$ Septicaemia & 15.4 & $2.9-81.1$ & 0.001 \\
$\quad$ Chronic renal failure & 4.1 & $1.3-12.6$ & 0.01 \\
$\quad$ Ischemic heart disease & 3.4 & $1.2-9.7$ & 0.02 \\
$\quad$ Age & 1.05 & $1.0-1.1$ & 0.004 \\
In-hospital mortality & & & \\
$\quad$ Septicaemia & 27.1 & $4.5-162.8$ & $<0.001$ \\
$\quad$ Warfarin & 16.7 & $2.1-132.5$ & 0.008 \\
$\quad$ Major stigmata of bleeding & 11.0 & $1.9-62.1$ & 0.007 \\
Recurrent bleeding & & & 0.006 \\
$\quad$ Adrenaline only & 4.4 & $1.5-12.7$ & 0.04 \\
$\quad$ Creatinine & 1.002 & $1.0-1.004$ & 0.002 \\
Need for surgery & & & 0.03 \\
$\quad$ Adrenaline only & 9.8 & $2.3-41.9$ & \\
Epigastric pain & 6.3 & $1.2-32.2$ & \\
\hline
\end{tabular}

Legend: LR; likelihood ratio, OR; adjusted odd ratio, CI; confidence interval 


\section{Figure 1}

Figure 1

The usefulness of Rockall score in predicting outcomes in non-variceal upper gastrointestinal bleeding in this ethnic Malay-majority population

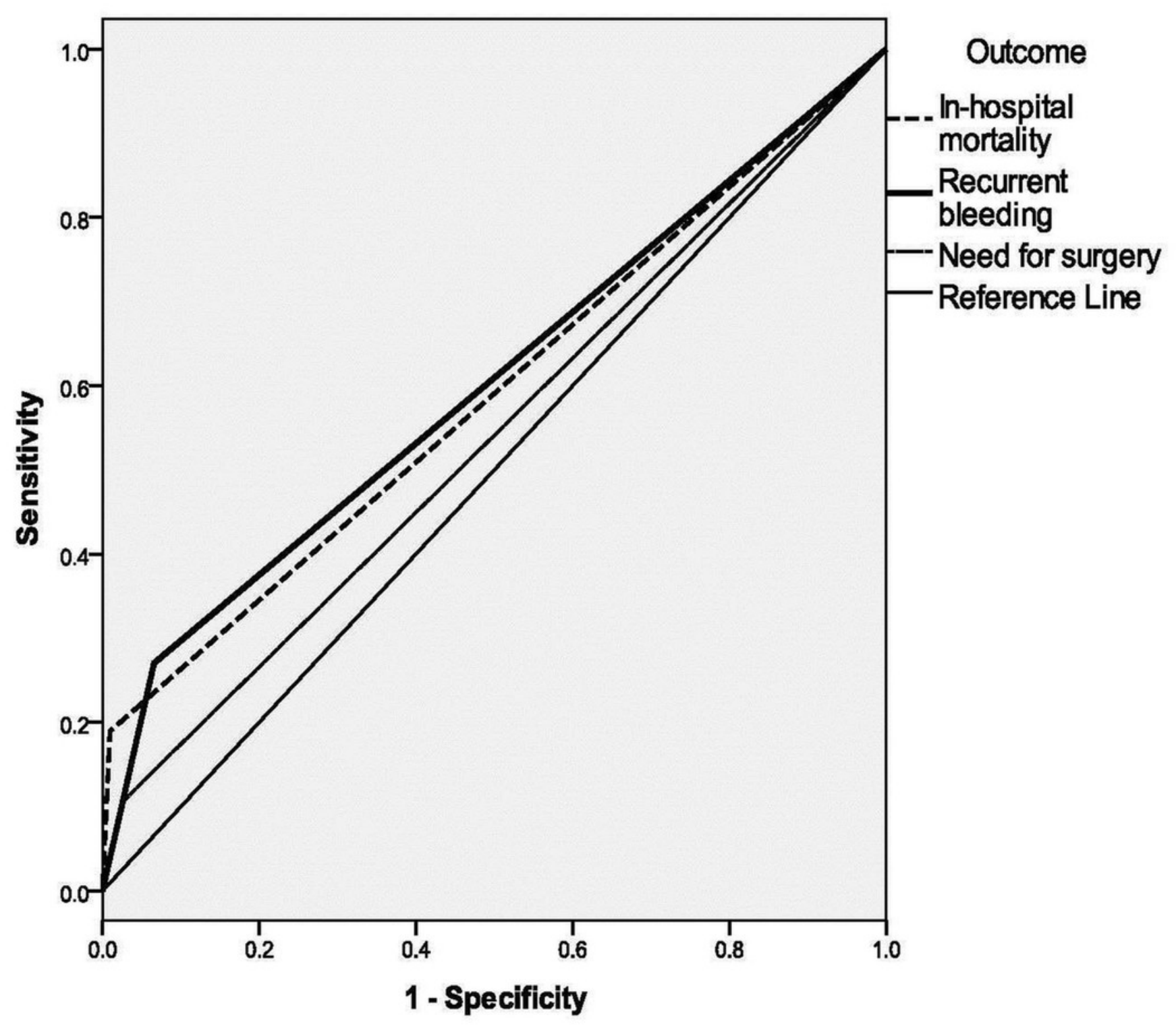

